\title{
Reserve albumin binding capacity, salicylate saturation index, and red cell binding of bilirubin in neonatal jaundice
}

\author{
DAG BRATLID \\ From the Paediatric Research Institute, University Hospital, Rikshospitalet, Oslo, Norway
}

\begin{abstract}
Bratlid, D. (1973). Archives of Disease in Childhood, 48, 393. Reserve albumin binding capacity, salicylate saturation index, and red cell binding of bilirubin in neonatal jaundice. 105 blood samples from 72 infants, mostly with jaundice due to haemolytic disease, were analysed for reserve albumin binding capacity (HBABA method), salicylate saturation index (SI), and red cell binding of bilirubin. 2 infants with clinical symptoms of bilirubin encephalopathy had abnormally large amounts of red cell bound bilirubin, though the HBABA binding capacity and salicylate saturation index did not suggest a risk of bilirubin encephalopathy. On the other hand, 48 of the other samples showed 'risk values' for saturation index and 2 of the other samples showed such values as judged by the HBABA method. The discrepancies between these findings are discussed. It is suggested that determination of red cell bound bilirubin may have clinical value in patients with neonatal jaundice, especially in cases of suggested kernicterus.
\end{abstract}

During recent years it has become clear that the capacity of albumin to bind bilirubin is limited. Most authors agree that one molecule of albumin can only bind tightly one molecule of bilirubin (Odell, 1959; Bjerrum, 1968; Jacobsen, 1969; Bratlid and Fog, 1970; Lie and Bratlid, 1970). Though additional bilirubin molecules may be bound to secondary sites on the albumin molecule, these molecules seem to be as toxic or even more toxic to cells as unbound bilirubin (Bratlid and Rugstad, 1972).

Several published reports show, however, that kernicterus may occur in infants with bilirubin concentrations far below the binding capacity of the high affinity albumin site (Harris, Lucey, and MacLean, 1968; Gartner et al., 1970). This can be explained by the competitive binding of several other substances on the albumin molecule (Odell, 1959; Bratlid, 1972c, d), and low $p \mathrm{H}$ has also been found to reduce the binding of bilirubin to albumin (Odell, 1965; Bratlid, 1972b). A determination of the real binding capacity of albumin for bilirubin is therefore needed, and for this purpose several methods have been described based on the competitive binding between bilirubin and other

Received 18 August 1972. compounds for the albumin molecule (Waters and Porter, 1961; Porter and Waters, 1966; Odell, Cohen, and Kelly, 1969; Howorth, 1971).

It is known that bilirubin is also bound to erythrocytes (Watson, 1962; Oski and Naiman, 1963), and it has been shown that this binding is markedly increased if there is a reduction in the capacity of albumin to bind bilirubin (Bratlid, 1972b, c, d). Measurement of this fraction of the total blood bilirubin might therefore serve as an indicator of the degree of saturation of the albumin molecule with bilirubin.

In the present report the amount of red cell bound bilirubin in cases of neonatal jaundice has been compared with the reserve HBABA (2(4' hydroxyazobenzene) benzoic acid) binding capacity (Porter and Waters, 1966) and the salicylate saturation index (Odell et al., 1969).

\section{Materials and methods}

Whole blood was obtained from icteric newborns at the time of exchange transfusion. Only the first blood drawn from the patient was used. Heparin was used as anticoagulant giving a final concentration of 125 to $250 \mathrm{IU} / \mathrm{ml}$. The blood was analysed immediately or stored in the dark for less than 20 hours before analysis. Plasma samples not analysed immediately were stored 
in the dark at $-15^{\circ} \mathrm{C}$. The indications for exchange transfusions were as described by Aagenaes (1967).

Determination of erythrocyte-bound bilirubin was performed as described elsewhere (Bratlid, 1972a). $1 \mathrm{ml}$ whole blood was washed three times in isotonic phosphate buffer-glucose $p \mathrm{H} 7 \cdot 4$ and the bilirubin bound by the cells was eluted by incubating the cells for 15 minutes in $2 \mathrm{ml}$ of a $3 \mathrm{~g} / 100 \mathrm{ml}$ solution of

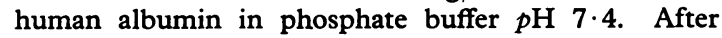
centrifugation the bilirubin concentration was determined in the supernatant, and the amount of bilirubin bound by the cells calculated from this and the haematocrit.

HBABA (2(4'hydroxyazobenzene) benzoic acid) binding capacity was determined as described by Porter and Waters (1966), using a $4 \mathrm{~g} / 100 \mathrm{ml}$ solution of albumin as reference.

The salicylate saturation index (SI) was determined as described by Odell et al. (1969).

Albumin concentrations were determined by radioimmunodiffusion (Partigen, Behringwerke). Bilirubin was determined by a modification of the method of Jendrassik and Grof (Fog, 1958).

Bilirubin was obtained from Koch-Light Laboratories. Albumin was obtained from Kabi, Sweden.

Spectrophotometric absorption curves were obtained using a Beckman DK-2A automatic spectrophotometer.

105 sera from 72 patients with neonatal jaundice were analysed. 5 samples were from patients with jaundice not related to haemolytic disease.

\section{Results}

Total plasma bilirubin concentration varied from $2 \cdot 2$ to $32 \cdot 0 \mathrm{mg} / 100 \mathrm{ml}$ with a mean of $12 \cdot 5 \mathrm{mg} /$ $100 \mathrm{ml}$. Albumin concentrations varied from $2 \cdot 0$ to $4 \cdot 3 \mathrm{~g} / 100 \mathrm{ml}$ with a mean of $3 \cdot 2 \mathrm{~g} / 100 \mathrm{ml}$.

Red cell bilirubin varied between $0.3 \mathrm{mg} / 100 \mathrm{ml}$ and $6.1 \mathrm{mg} / 100 \mathrm{ml}$ Two of the samples showed a much higher erythrocytic binding of bilirubin than all the others with levels of $6 \cdot 1$ and $4 \cdot 4 \mathrm{mg} / 100 \mathrm{ml}$, respectively. Both these patients had plasma bilirubin/albumin molar ratios above unity, and at the time of sampling showed signs of bilirubin encephalopathy. The patient with a red cell binding of bilirubin of $6 \cdot 1 \mathrm{mg} / 100 \mathrm{ml}$ later died, and kernicterus was confirmed at necropsy. The other patient improved after albumin administration and several exchange transfusions. 2 months after discharge from hospital the infant's neurological status was not known.

Fig. 1 shows that a correlation exists between the amount of red cell bound bilirubin and the molar bilirubin/albumin ratio in the plasma samples, as would be expected from in vitro experiments (Bratlid, 1972a).

The HBABA binding capacity of the plasma samples is shown in Fig. 2. The values ranged from 6 to 92. Two samples showed a reserve

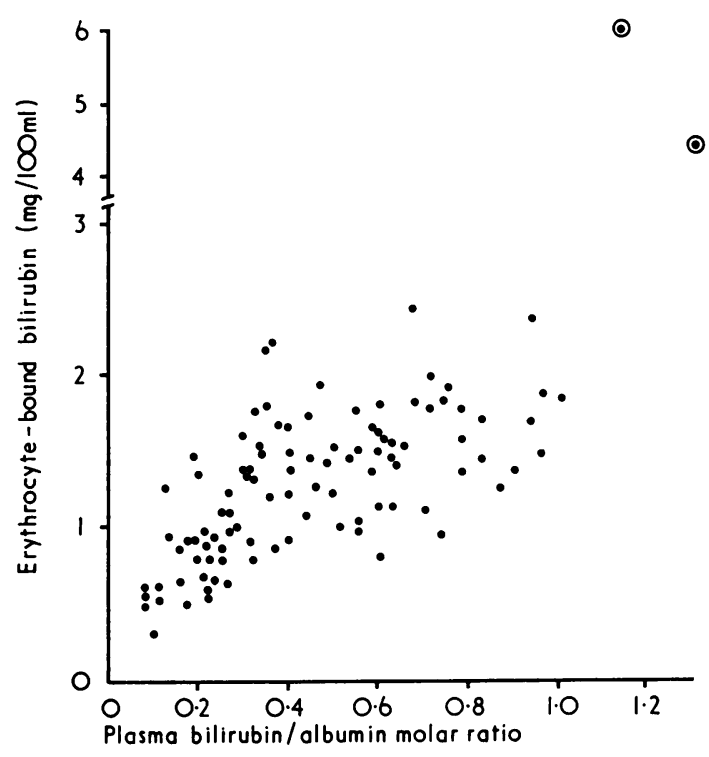

FIG. 1.-Relation between erythrocyte-bound bilirubin and the molar bilirubin/albumin ratios of the plasma samples. $\odot$ represents values obtained from two patients with symptoms of bilirubin encephalopathy at the time of sampling.

dye-binding capacity below 25, which most authors consider is indicative of the development of kernicterus (Porter and Waters, 1966; Priolisi and Ziino, 1971). These patients had, however, no special clinical signs of bilirubin encephalopathy, and their serum bilirubin concentrations were only moderately raised, $7 \cdot 1$ and $15 \mathrm{mg} / 100 \mathrm{ml}$, respectively, with correspondingly low plasma bilirubin/ albumin ratios. On the other hand, the 2 patients with clinical signs of bilirubin encephalopathy had HBABA values which were not significantly lower than those of other patients.

The salicylate saturation index (SI) of the plasma samples is shown in Fig. 2. The values varied from 0.2 to $20 \cdot 7$. No correlation was found between the SI and the molar bilirubin/albumin ratio of the samples. This is in agreement with the findings of Odell et al. (1969) for samples from patients with haemolytic disease. 48 of the samples had SI values above 8 , suggesting that these patients were likely to develop bilirubin encephalopathy (Odell et al., 1969). This is in sharp contrast to the observation that only two patients were at risk judged by the HBABA method, and that of these two patients only one also had high SI. Moreover, the two patients with clinical 


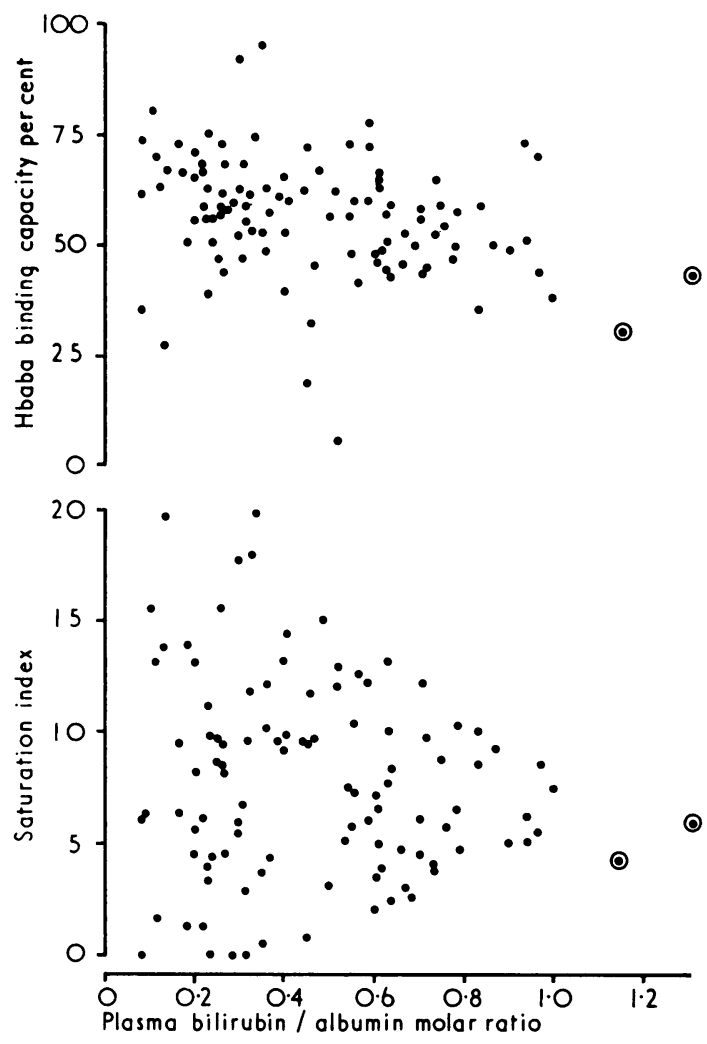

FIG. 2.-Relation between the reserve $H B A B A$ binding capacity (upper part) and the salicylate saturation index (SI) (lower part) and the molar bilirubin/albumin ratios of the plasma samples. $\odot$ represents values obtained from two patients with symptoms of bilirubin encephalopathy at the time of sampling.

bilirubin encephalopathy both had 'normal' SI (Fig. 2).

\section{Discussion}

The vahues for red cell binding of bilirubin correlate satisfactorily with those for the molar bilirubin/albumin ratio (Fig. 1). This is in agreement with earlier in vitro studies (Kaufmann, Simcha, and Blondheim, 1967; Bratlid, 1972a), though the wide scatter of the results suggests that several other factors also influence the binding of bilirubin.

The only 2 patients with bilirubin encephalopathy at the time of sampling had values for red cell bilirubin which were well above those found in the other patients. With certain reservations it thus seems as if the red cell concentration of bilirubin correlates well with the clinical findings. Judged from the present results, the HBABA binding capacity is not very useful in finding out which children are in danger of developing kernicterus and which are not. The 2 infants with signs of bilirubin encephalopathy did not differ significantly from many other infants in their HBABA binding (Fig. 2). On the other hand, several authors have reported the HBABA binding tests to be useful (Porter and Waters, 1966; Priolisi and Ziino, 1971; Svenningsen, Lindquist, and Dahlquist, 1971), though some variation exists between the HBABA binding value which is considered to be indicative of risk for bilirubin encephalopathy. It has, however, been shown (Priolisi and Ziino, 1971) that measurement of dye-binding capacity is not a specific measurement of bilirubin binding but more a measure of the total binding capacity of the albumin molecule for organic anions. Lucey, Valaes, and Doxiadis (1967) thus found no correlation between the binding of phenolsulphonphthalein (PSP) and bilirubin concentrations in cases of neonatal jaundice. The results for the dyebinding capacity did not correlate with their clinical findings.

The salicylate saturation index (SI) was found not to be useful in selecting the infants likely to develop kernicterus from the others (Fig. 2). As mentioned, 48 of the samples had SI values above 8 , suggesting that these patients were likely to develop bilirubin encephalopathy. In addition, 5 samples, mostly with low plasma bilirubin concentrations, showed SI values above 14, which has been given as the highest value obtainable in this test, indicating complete saturation of the albumin molecule (Odell et al., 1969). However, the basis for this method is measurement of the spectrophotometric differences which exist between bilirubin bound to albumin and unbound bilirubin at $p \mathrm{H} 7 \cdot 4$. This is based on two assumptions. Firstly, it implies that unbound bilirubin should exist as such at $p \mathrm{H} 7 \cdot 4$ in high enough concentrations for spectrophotometric registrations, and secondly, that salicylate displaces bilirubin completely from the albumin molecule. Both of these assumptions may be wrong.

Firstly, the extremely low solubility of bilirubin at physiological $p \mathrm{H}$ (Brodersen and Theilgaard, 1969) makes it impossible for bilirubin to exist unbound in solution in any significant concentration; crystallization will rapidly take place (Brodersen and Theilgaard, 1969; Bratlid and Fog, 1970). As shown in Fig. 3 and also reported earlier by others (Bratlid and Fog, 1970; Brodersen et al., 1972), this crystallization is reflected by a drop in maximum optical density and an increase in absorbance at wave lengths above $500 \mathrm{~nm}$. The 
absorbance curves for unbound bilirubin given by Odell et al. (1969) are much like the 5-minute curve in Fig. 3, but it is probably not correct to

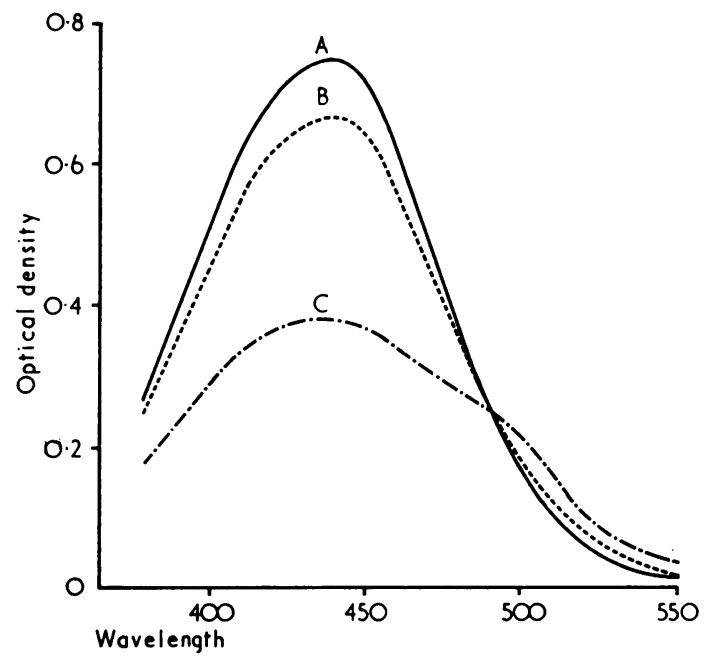

FIG. 3.-Light absorption spectra of a solution of bilirubin in $0.05 \mathrm{~N} \mathrm{NaOH}$ diluted to $15 \mu \mathrm{mol} / \mathrm{l}$. with $0.1 \mathrm{~mol} / \mathrm{l}$. phosphate buffer $\mathrm{pH} 7 \cdot 4$ determined after varying lengths of time. During the time of observation only approximately a $10 \%$ drop in bilirubin concentration was found. $A$, Immediately; $B, 5$ minutes; $C, 1$ hour.

use this curve as a reference curve for unbound bilirubin without reservations.

The second assumption in the SI method is that salicylate causes complete displacement of bilirubin from the albumin molecule. However, as recently reported by Brodersen (1972), salicylate seems to displace bilirubin from the primary binding site onto the secondary binding sites with the successive formation of bilirubin-albumin co-crystals composed of approximately $200 \mathrm{~mol}$ bilirubin per mol albumin. Bilirubin molecules bound to secondary sites on the albumin molecule, though very unstable, seem to have a higher maximum optical density and at a slightly higher wavelength than when bound at the primary site (Bratlid and Fog, 1970; Brodersen et al., 1972), in fact, almost the opposite spectral changes to the reference curve given for the saturation index method (Odell et al., 1969). Even if this curve should be useful as a curve for unbound bilirubin, as doubted above, it can therefore probably not be used as a reference for the effect of salicylate displacement of bilirubin since addition of salicylate does not give unbound bilirubin. Until this problem has been elucidated, it seems difficult to evaluate the spectrophotometric alterations of a serum sample caused by the addition of salicylate, and perhaps other changes than those occurring at $460 \mathrm{~nm}$ may be more interesting.

Exchange transfusion is an effective and relatively safe treatment of hyperbilirubinaemia in the newborn, and different tests have been designed to improve on the selection of patients for this treatment. On the basis of the present findings, neither the reserve HBABA dye-binding test nor the salicylate saturation index seems useful for this purpose. In addition, both these methods from a theoretical point of view have limitations which make it difficult to evaluate the results produced. Measurement of red cell bilirubin may have several advantages. At least it seems possible by this procedure to obtain information about the degree of saturation of the albumin molecule without introducing any foreign substances. In the present study this method also discriminated well between the two patients with bilirubin encephalopathy and all the other patients. If this finding can be confirmed in a larger number of patients, the method could possibly be of diagnostic and prognostic value in infants already showing suspicious signs of bilirubin intoxication.

\section{REFERENCES}

Aagenaes, Ø. (1967). Behandling av erythroblatosis foetalis. Tidsskrift for den Norske Laegeforening, 87, Suppl. 1581.

Bjerrum, O. J. (1968). Interaction of bromphenol blue and bilirubin with bovine and human serum albumin determined by gel filtration. Scandinavian fournal of Clinical and Laboratory Investigation, 22, 41.

Bratlid, D. (1972a). Bilirubin binding by human erythrocytes. Scandinavian fournal of Clinical and Laboratory Investigation, 29, 91 .

Bratlid, D. (1972b). The effect of $\mathrm{pH}$ on bilirubin binding by human erythrocytes. Scandinavian fournal of Clinical and Laboratory Investigation, 29, 453.

Bratlid, D. (1972c). The effect of free fatty acids, bile acids, and hematin on bilirubin binding by human erythrocytes. Scandinavian fournal of Clinical and Laboratory Investigation, 30, 107.

Bratlid, D. (1972d). The effect of antimicrobial agents and salicylate on bilirubin binding by human erythrocytes. Scandinavian fournal of Clinical and Laboratory Investigation, 30, 331.

Bratlid, D., and Fog, J. (1970). The binding capacity of human albumin for bilirubin and its significance in the pathogenesis of kernicterus. Scandinavian fournal of Clinical and Laboratory Investigation, 25, 257.

Bratlid, D., and Rugstad, H. E. (1972). Effect of albumin binding on bilirubin conjugation and toxicity in a clonal strain of rat hepatoma cells. Scandinavian fournal of Clinical and Laboratory Investigation, 29, 461.

Brodersen, R. (1972). Supersaturation with bilirubin followed by colloid formation and disposition, with hypothesis on the etiology of kernicterus. Scandinavian fournal of Clinical and Laboratory Investigation, 29, 447.

Brodersen, R., Funding, L., Pedersen, A. O., and RöigaardPetersen, H. (1972). Binding of bilirubin to low affinity sites of human serum albumin in vitro followed by co-crystallization. Scandinavian fournal of Clinical and Laboratory Investigation, 29, 433.

Brodersen, R., and Theilgaard, J. (1969). Bilirubin colloid formation in neutral aqueous solution. Scandinavian fournal of Clinical and Laboratory Investigation, 24, 395. 
Fog, J. (1958). Determination of bilirubin in serum as alkaline 'azobilirubin'. Scandinavian fournal of Clinical and Laboratory Investigation, 10, 241.

Gartner, L. M., Snyder, R. N., Chabon, R. S., and Bernstein, J. (1970). Kernicterus: high incidence in premature infants with low serum bilirubin concentrations. Pediatrics, 45, 906.

Harris, R. C., Lucey, J. F., and MacLean, J. R. (1958). Kernicterus in premature infants associated with low concentrations of bilirubin in the plasma. Pediatrics, 21, 875 .

Howorth, P. J. N. (1971). Determination of serum albumin in neonatal jaundice. The albumin saturation index. Clinica Chimica Acta, 32, 271.

Jacobsen, J. (1969). Binding of bilirubin to human serum albumin -determination of the dissociation constants. FEBS Letters, $5,112$.

Kaufmann, N. A., Simcha, A. J., and Blondheim, S. H. (1967). The uptake of bilirubin by blood cells from plasma and its relationship to the criteria for exchange transfusion. Clinical Science, 33, 201.

Lie, S. O., and Bratlid, D. (1970). The protective effect of albumin on bilirubin toxicity on human fibroblasts. Scandinavian fournal of Clinical and Laboratory Investigation, 26, 37.

Lucey, J. F., Valaes, T., and Doxiadis, S. A. (1967). Serum albumin reserve PSP dye binding capacity in infants with kernicterus. Pediatrics, $\mathbf{3 9}, \mathbf{8 7 6}$.

Odell, G. B. (1959). The dissociation of bilirubin from albumin and its clinical implications. Fournal of Pediatrics, 55, 268.

Odell, G. B. (1965). Influence of $\mathrm{pH}$ on the distribution of bilirubin between albumin and mitochondria. Proceedings of the Society for Experimental Biology and Medicine, 120, 352.
Odell, G. B., Cohen, S. N., and Kelly, P. C. (1969). Studies in kernicterus. II. The determination of the saturation of serum albumin with bilirubin. Fournal of Pediatrics, 74, 214.

Oski, F. A., and Naiman, J. L. (1963). Red cell binding of bilirubin. Fournal of Pediatrics, 63, 1034.

Porter, E. G., and Waters, W. J. (1966). A rapid micromethod for measuring the reserve albumin binding capacity in serum from newborn infants with hyperbilirubinemia. Fournal of Laboratory and Clinical Medicine, 67, 660.

Priolisi, A., and Ziino, L. (1971). Comparative analysis between the reserve albumin-binding capacity (HBABA method) and the saturation index of hyperbilirubinaemic sera. Biology of the Neonate, 18, 258.

Svenningsen, N. W., Lindquist, B., and Dahlquist, A. (1971). HBABA index in neonatal jaundice. In Proceedings of the XIIIth International Congress of Pediatrics, Vol. I, p. 353. Published by the Vienna Academy of Medicine, Vienna.

Waters, W. J., and Porter, E. G. (1961). Dye-binding capacity of serum albumin in hemolytic disease of the newborn. American Fournal of Diseases of Children, 102, 807.

Watson, D. (1962). The absorption of bilirubin by erythrocytes. Clinica Chimica Acta, 7, 733.

Correspondence to Dr. Dag Bratlid, Paediatric Research Institute, University Hospital, Rikshospitalet, Oslo, Norway. 